Cumhuriyet International Journal of Education-CIJE

e-ISSN: 2147-1606

Vol 3 (3), 2014, $54-67$

\title{
A New Approach in the Domain of Education: Strengths-based Approach
}

\author{
Emrullah YILMAZ1, Burhan AKPINAR ${ }^{2}$
}

\section{Summary}

SBA is different from the other approaches in that all of the other approaches focus on weaknesses of individuals and are grouped as "Deficit Remediation Educational Models" (Anderson, 2004; Clifton, Anderson and Schreiner, 2006; Schreiner and Anderson, 2005) whereas SBA focuses on talents and strengths of individuals. SBA concentrates on what individuals have rather than what they don't. The basic tenet is that the talents and strengths of individuals can be used in the process of learning and teaching.

Donald O. Clifton founded the theoretical basis of SBA and Edward Chip Anderson implemented it especially in higher education. Both of them were eminent professors in the field of psychology. At a conference in 1978, Clifton and Anderson met for the first time and Clifton's sentence "to produce excellence, you must study excellence" (Clifton, Anderson, Schreiner, 2006: xv) changed Anderson's personal consideration about education.

In the years following the World War II, most of the psychologists focused on illnesses and traumas caused by the devastating war (Gable and Haidt, 2005; Seligman and Csikszentmihalyi, 2000). This case bothered some psychologists like Martin E.P. Seligman and Positive Psychology Movement emerged as a reaction. Clifton contributed to this process with his sentence "what if we studied what is right with people" (Hodges, 2009: 172).

The concept of positive psychology was first mentioned in 1998 by Martin E.P. Seligman at a meeting of American Psychology Association. As is stated above, it dates back to 1950s and it is a result of the reactions against the inclinations of most of the psychologists towards psychological diseases after World War II. The aim of positive psychology movement is to determine first and then develop the human strengths and useful traits that make life worth living (Froh, 2004). The focus of positive psychology on positive human traits inspired strengths-based approach.

SBA brings about a serious change of paradigm with respect to the consideration of learners. As Schreiner and Anderson (2005: 22) suggest "focusing on student deficits and needs is focusing on the student who is not there. However, through a strengths-based approach, the advisor works with the student who is there". One of the major features of SBA is to determine and develop what individuals have in learning teaching process. Positive characteristics of people can play a facilitating role during learning teaching process. The basic assumption of this approach is that all the students have a potential and teachers invent and implement ways so as to discover the potential of students. SBA not only focuses on the strengths of students but also those of educators as well.

Talent themes of individuals are determined through Clifton Strengthsfinder ${ }^{\mathrm{TM}}$, a web based psychometric test. The five dominant talent themes are determined for each of the individuals and they are improved using their knowledge and skills up to perfection. When the talents and strengths of individuals are assigned importance by educators, students will think that "their bucket is not empty" (Rath and Clifton, 2007) and thus they will feel that they are not at zero when they need to achieve something.

A talent is "a naturally recurring pattern of thought, feeling or behaviour that can be productively applied" (Clifton et al., 2006: 2). And talent theme is a group of similar talents. Strength is "the ability to provide consistent, near-perfect performance in a given activity"

\footnotetext{
${ }^{1}$ Ins. PhD., Bartın University, Department of Foreign Languages, emrullahyilmaz@bartin.edu.tr

2 Assoc. Prof., Frrat University, Faculty of Education, bakpinar@firat.edu.tr
} 
(Clifton et al., 2006: 4). There are 34 themes of talent measured by Clifton Strengthsfinder and when the five signature themes of an individual are determined, that individual is assisted in converting his/her talents into strengths by improving them using knowledge and skills.

Using SBA in education is a serious change of paradigm in that it fundamentally changes educators' viewpoint about learners. The main principle of SBA is that learners come to school or where they are to be educated with some talents that can be made use of during the learning and teaching process. When their talents are determined and improved with knowledge and skills, the learners can take the responsibility of their own learning and will be more motivated. The benefits of using SBA in education have been examined in some studies especially in USA. Additional experimental studies should be conducted in other parts of the world and especially in Turkey so as to test the efficiency of this approach.

SBA is a different viewpoint that can provide a fundamental insight in the domain of education. Therefore, more studies should be carried out on SBA both in the world and in Turkey if it is to be an alternative approach that can help to overcome problems encountered in education. 